\title{
ANÁLISE DO RELATÓRIO AMBIENTAL PRÉVIO (RAP) DO COMPLEXO EMPRESARIAL E RESIDENCIAL TANGUÁ PATRIMONIAL (CURITIBA/PR) COM BASE NOS PRINCÍPIOS DO PLANEJAMENTO DA PAISAGEM
}

\author{
Laura Freire Estêvez ${ }^{1}$
}

\author{
João Carlos Nucci ${ }^{2}$
}

\author{
Simone Valaski ${ }^{3}$
}

\begin{abstract}
RESUMO
O Planejamento da Paisagem aplicado ao meio urbanizado tem como um dos princípios a manutenção ou melhoria da qualidade ambiental urbana, que pode ser diminuída com a crescente instalação de empreendimentos na cidade. Para avaliar os impactos ambientais desses empreendimentos antes da sua instalação, o Estatuto da Cidade (BRASIL, 2001) instituiu o Estudo Prévio de Impacto de Vizinhança - EIV. O Município de Curitiba realiza estudos de impactos ambientais de empreendimentos e suas atividades desde $1997 \mathrm{com}$ o estabelecimento do Relatório Ambiental Prévio - RAP (CURITIBA, 1997). O objetivo do trabalho foi o de analisar o RAP do Complexo Empresarial e Residencial Tanguá Patrimonial (Curitiba, PR) com base nos princípios do Planejamento da Paisagem e com isso fornecer subsídios para a reflexão sobre a possibilidade de um planejamento urbano que considere a qualidade ambiental. Para a avaliação do RAP foram definidos critérios e parâmetros, com base nos estudos de qualidade ambiental urbana (NUCCl, 1996), nos estudos sobre cidades saudáveis da Organização Mundial da Saúde e em princípios da Flor da Permacultura. Apesar de tratar sobre alguns impactos ambientais negativos de forma superficial, o RAP não contemplou a grande maioria dos impactos ambientais negativos relacionados à Qualidade Ambiental Urbana e, mesmo assim, forneceu diagnóstico favorável ao empreendimento.
\end{abstract}

PALAVRAS-CHAVE:Qualidade ambiental urbana.Planejamento da Paisagem. Estudo Prévio de Impacto de Vizinhança.

\footnotetext{
${ }^{1}$ Geógrafa e mestre pela Universidade Estadual de Maringá (UEM), doutora em Geografia na área de Paisagem e Análise Ambiental pela Universidade Federal do Paraná (UFPR). E-mail: laurafreire.geo@gmail.com.

${ }^{2}$ Biólogo (IB-USP), doutor em Geografia Física pela Universidade de São Paulo (DG-FFLCH-USP) e professor do Departamento de Geografia da UFPR. E-mail: nucci@ufpr.br.

${ }^{3}$ Geógrafa, mestre e doutora em Geografia na área de Paisagem e Análise Ambiental pela UFPR. Professora do Setor de Educação Profissional e Tecnológica - SEPT/UFPR. E-mail: valaski@ufpr.br.
} 


\title{
ANALYSIS OF PREVIOUS ENVIRONMENTAL REPORT OF BUSINESS COMPLEX AND RESIDENTIAL TANGUÁ PATROMONIAL (CURITIBA/PR) BASED ON THE PRINCIPLES OF LANDSCAPE PLANNING
}

\begin{abstract}
The Landscape Planning applied to the urbanized environment has as one of its principles the maintenance or improvement of urban environmental quality, which can be decreased with the increasing construction of enterprises in the city. To evaluate the environmental impacts of these enterprises before their construction, the Brazilian federal act (BRAZIL, 2001) established the Preliminary Study of Neighborhood Impact. The city of Curitiba had performed environmental impact studies of enterprises and its activities since 1997, with the Previous Environmental Report. The objective of this study was to analyze the Previous Environmental Report of Business Complex and Residential Tanguá Patrimonial (Curitiba, PR) based on the principles of Landscape Planning and thereby provide subsidies to reflect on the possibility of an urban planning that considers the environmental quality. For the evaluation it was defined criteria and parameters based on studies of urban environmental quality (NUCCl, 1996), in studies on healthy cities of the World Health Organization and principles of Permaculture Flower. Despite of treating about some negative environmental impacts in a very superficial way, the study did not include the vast majority of negative environmental impacts related to Urban Environmental Quality and still provided favorable diagnostic to the enterprise.
\end{abstract}

KEY-WORDS: Urban Environmental Quality. Landscape Planning. Preliminary Study of Neighborhood Impact.

\section{ANÁLISIS DE LO INFORME AMBIENTAL PRELIMINAR DE LO COMPLEJO DE NEGOCIO Y RESIDENCIAL TANGUÁ PATRIMONIAL (CURITIBA / PR) BASADO EN LOS PRINCIPIOS DE PLANIFICACIÓN DEL PAISAJE}

\begin{abstract}
RESUMEN
La PlanificacióndelPaisaje aplicada al medio urbanizado tiene como uno de los principios el mantenimiento o la mejora de la calidad del medio ambiente urbano, que puede ser disminuido con la instalación de empresas en la ciudad. Para evaluarel impacto ambiental de losproyectos antes de lainstalación, el Estatuto de laCiudad (BRASIL, 2001) instituyóEstudioPrevio de Impacto de su entorno. La Municipalidad de Curitiba realiza estudios sobre los impactos ambientales de los proyectos y actividades a partir de 1997 con elestablecimientodel Informe Ambiental Previo(Curitiba, 1997). El objetivo de lo artículo ha sidoanalizarel Informe Ambiental Previodelcomplejoempresarial y residencial Tanguá Patrimonial (Curitiba, PR), basadoenlosprincipios de PlanificacióndelPaisaje y asíproporcionar una base para reflexionar sobre laposibilidad de una planificación urbana que considere la calidad ambiental. Para la evaluación de lo Informe Informe Ambiental Previose
\end{abstract}


establecieroncriterios y parámetros, basados en estudios de calidad ambiental urbana (NUCCI, 1996), en los estudios de ciudades saludables de la Organización Mundial de la Salud y de los principios de la Flor de la Permacultura. A pesar de tratar sobrealgunos de los impactos ambientales negativos de manera superficial, ellnforme Ambiental Previono consideró una gran parte deimpactos ambientales negativos relativos a lacalidad ambiental urbana e, igualmente, emitiódiagnóstico favorable a la empresa.

PALABRAS-CLAVE:Calidad Ambiental Urbana. Planificación del Paisaje. Estudio Preliminar de Impacto Alrededor.

\section{INTRODUÇÃO}

Os empreendimentos e atividades instalados na cidade podem provocar impactos ambientais negativos e/ou positivos. Para analisar estes impactos são elaborados estudos de avaliação de impactos ambientais urbanos. Estes instrumentos da política urbana ${ }^{4}$, que avaliam os impactos ambientais, têm potencial para contribuir para um planejamento urbano voltado a uma cidade saudável e preocupado com a qualidade ambiental urbana.

Do mesmo modo, os estudos sobre a qualidade ambiental urbana fornecem subsídios para entender os problemas ambientais decorrentes do acelerado processo de crescimento das cidades contemporâneas. Com base nas avaliações da qualidade ambiental urbana é possível tomar decisões de planejamento e gestão que busquem diminuir ou mesmo evitar os impactos causados por ações antrópicas sobre o ambiente urbano.

Em Curitiba o estudo de avaliação de impactos ambientais urbanos, destacado neste trabalho, é o Relatório Ambiental Prévio (RAP), mas esses estudos podem não estar garantindo a qualidade do ambiente urbano para a população local.Assim, o presente trabalho teve como objetivo analisaro RAP do Complexo Empresarial e Residencial Tanguá Patrimonial, localizado em Curitiba/PR, com base nos princípios do Planejamento da Paisagem.

\footnotetext{
${ }^{4}$ Em Estêvez (2014), pode-se encontrar um histórico dos estudos de avaliação de impactos ambientais urbanos no Brasil e em Curitiba; o trabalho ainda detalha o surgimento do Estatuto da Cidade (BRASIL, 2001) e do Estudo Prévio de Impacto de Vizinhança (EIV).
} 
Revista Nacional de

Gerenciamento de Cidades

A área destacada na Figura 1 representa um setor significativo do bairro, em que pelo uso não há residentes, esse é um dos motivos do bairro Centro Cívico ter um número baixo de habitantes. As características apresentadas diferenciam o bairro em relação aos demais bairros do município. Então, pode acontecer dos impactos de empreendimentos instalados no bairro Centro Cívico indicarem que não há impactos relevantes sobre o bairro, mas os impactos podem recair sobre os bairros vizinhos, o Centro, por exemplo, ou mesmo sobre o município como um todo.

Para analisar o RAP foram definidos critérios de avaliação da qualidade ambiental urbana com base nos estudos de qualidade ambiental urbana ( $\mathrm{NUCCl}$, 1996; 2008), estudos sobre cidades saudáveis da Organização Mundial da Saúde (BARTON e TSOUROU, 2000), e em alguns princípios extraídos da Flor da Permacultura (HOLMGREEN, 2001).

A partir de revisão bibliográfica dos estudos de qualidade ambiental urbana foram definidos os critérios Espaços Livres, Cobertura Vegetal, Verticalidade das Edificações e Usos Potencialmente Poluidores. Os critérios Estilos de Vida Saudável e Pegada Ecológica foram inseridos na análise sob a influência dos estudos sobre cidades saudáveis e dos princípios da Flor da Permacultura.

Cada um dos critérios foi analisado com base nos seguintes parâmetros préestabelecidos:

- Espaços Livres: presença de aspectos sobre a proporcionalidade dos espaços urbanos. Parâmetro de referência: $40 \%$ para espaços livres de edificação;

- Cobertura Vegetal: presença de aspectos sobre o critério, como o índice de cobertura vegetal em $\mathrm{m}^{2} / \mathrm{hab}$. ou em porcentagem. Parâmetro de referência: $30 \%$ de cobertura vegetal;

- Verticalidade das Edificações: presença de aspectos sobre as edificações na bacia e discussão, como a concentração de edifícios e o número de pavimentos. Parâmetro de referência: acima de 4 pavimentos;

- Usos Potencialmente Poluidores: presença de aspectos sobre potenciais usos poluidores (poluição do ar, da água, do solo, aumento de tráfego de 


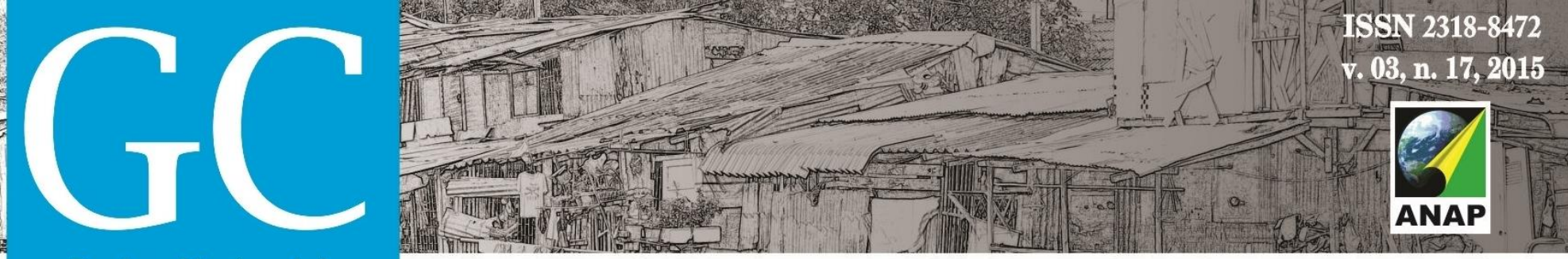

\section{Revista Nacional de}

Gerenciamento de Cidades

veículos, armazenamento de substâncias químicas e tóxicas). Parâmetro de referência: identificação de todos os usos potencialmente poluidores do bairro;

- Estilos de Vida Saudável: presença de aspectos do sistema de movimentação (viário, ciclovia, caminhada, pontos de ônibus), presença de sugestão de outras opções de instalação para o local do empreendimento. Parâmetro de referência: fatores relacionados a promover uma cidade saudável;

- Pegada Ecológica: presença de aspectos sobre o fluxo de matéria e energia relacionado ao empreendimento, aspectos sobre consumo de recursos naturais, destinação de resíduos. Parâmetro de referência: impactos negativos relacionados ao fluxo de matéria e energia.

Para a análise do RAP foi realizada uma abordagem qualitativa, com o método de aplicação de um formulário no formato de uma lista de checagem. Enfim, com os critérios definidos, o documento (RAP) foi analisado.

\section{RESULTADOS E DISCUSSÃO}

A Tabela 1 apresenta a síntese da análise realizada no RAP. 


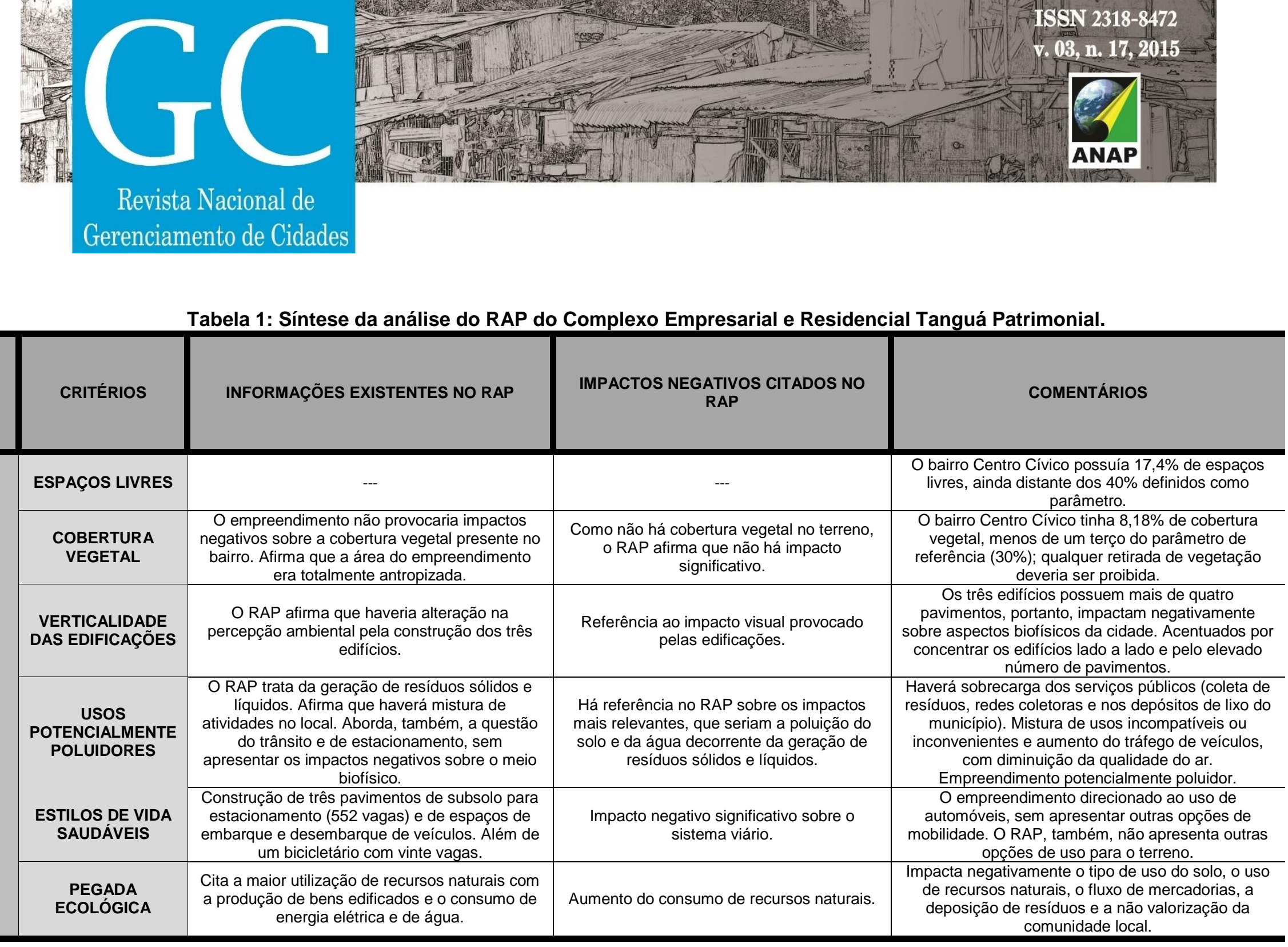

Elaboração: Laura Freire Estêvez (2014). 
Revista Nacional de

Gerenciamento de Cidades

O RAP compara o índice de áreas verdes recomendado pela Organização Mundial da Saúde (OMS), que é de $12 \mathrm{~m}^{2} /$ hab. para áreas urbanas com o índice de áreas verdes do bairro Centro Cívico que é de $16,6 \mathrm{~m}^{2} / \mathrm{hab}$., assim sendo, o RAP afirma que o bairro possui mais áreas verdes por habitante do que a quantidade sugerida pela OMS.

O índice da OMS é frequentemente citado em diversos trabalhos científicos como alusão ao índice ideal por ser sugerido por uma agência subordinada a Organização das Nações Unidas (ONU), mas a referência de onde foi extraída a informação é desconhecida, deixando uma certeza, de queestanão pode ser uma referência de índices de áreas verdes em $\mathrm{m}^{2} / \mathrm{hab}$.

Cavalheiro e Del Picchia(1992) investigaram a questão:

É muito difundida e arraigada no Brasil a assertiva de que a ONU, ou a OMS, ou a FAO, considera ideal que cada cidade dispusesse de $12 \mathrm{~m}^{2}$ de área verde/habitante. Nas pesquisas por carta que fizemos junto à essas organizações, foi constatado que esse índice não é conhecido, como não o é, entre as faculdades de paisagismo da República Federal da Alemanha. Somos levados a supor, depois de termos realizado muitos estudos, que esse índice se refira tão somente às necessidades de parque de bairro e distritais/setoriais, já que são os que, dentro da malha urbana, devem ser sempre públicos e oferecem possibilidade de lazer ao ar livre (CAVALHEIRO E DEL PICCHIA, 1992).

Outra questão é a confusão conceitual, pois as áreas verdes citadas pela OMS tratam de uma categoria dos espaços livres e as áreas verdes apresentadas pela prefeitura de Curitiba representa a cobertura vegetal ${ }^{6}$. Este aspecto merece atenção, seria preciso que os conceitos fossem pré-definidos para a elaboração dos estudos de avaliação de impactos ambientais, assim, evitando confusões conceituais e numéricas.

Por suas peculiaridades o bairro Centro Cívico apresenta um bom índice de espaços livres $\left(34,05 \mathrm{~m}^{2} / \mathrm{hab}\right.$.), como mostrado no tópico anterior, e o índice de cobertura vegetal calculado pelo IPPUC (2010) é de $16,6 \mathrm{~m}^{2} / \mathrm{hab}$., assim sendo,

\footnotetext{
${ }^{6}$ De acordo com o Plano Municipal de Controle Ambiental e Desenvolvimento Sustentável ${ }^{6}$ do Município de Curitiba (2007, p. 39 e 40), as áreas verdes referem-se à cobertura florestal.
} 
haveria mais espaços livres do que cobertura vegetal no bairro, que pode ser explicado pela presença de grandes áreas de jardins que circundam as edificações públicas, além das praças com áreas cobertas por vegetação herbácea ou, mesmo, sem vegetação.

Como no bairro Centro Cívico há $34,05 \mathrm{~m}^{2} / \mathrm{hab}$. de espaços livres, que correspondem a $17,4 \%$ da área do bairro, o índice de cobertura vegetal de $16,6 \mathrm{~m}^{2} /$ hab. calculados em porcentagem representam $8,18 \%\left(78.722 \mathrm{~m}^{2}\right)$ da área total do bairro. $O$ índice de cobertura vegetal $(8,18 \%)$ do bairro é menos de um terço do parâmetro de referência $(30 \%)^{7}$, de tal modo, qualquer retirada de vegetação deveria ser proibida ou compensada efetivamente e medidas para aumentar a cobertura vegetal no bairro Centro Cívico deveriam ser tomadas.

Depois de comparados os índices da OMS com o do IPPUC, o RAP conclui que o empreendimento não provocaria impactos negativos significativos sobre a cobertura vegetal presente no bairro, diferente do mostrado na comparação entre o índice de cobertura vegetal e o parâmetro definido.

Ao tratar especificamente sobre a área do empreendimento o RAP afirma que a área era totalmente antropizada e comenta a existência de dois indivíduos de jerivás (palmeira nativa da mata atlântica) com 10 e 12 metros no terreno em questão. Segundo o RAP, a localização dos jerivás indica que eles foram introduzidos no local, afirmando que não seriam remanescentes de mata atlântica original, comum na região.

Ao avaliar a área como antropizada o RAP conclui que a instalação do empreendimento não impactaria negativamente sobre a fauna e a flora local, mesmo retirando a vegetação existente e aumentando os espaços edificados. $\mathrm{O}$ argumento de que a área já era antropizada deve ser combatido, pois, senão, toda área no meio urbano será assim considerada e poderá receber edificação.

\footnotetext{
${ }^{7}$ De acordo com Oke (apud Lombardo, 1985) estima que um índice de cobertura vegetal na faixa de $30 \%$ seja o recomendável para proporcionar um adequado balanço térmico em áreas urbanas, e áreas com um índice de arborização inferior a 5\% determinam características semelhantes às de um deserto.
} 


\section{Revista Nacional de}

que agindo negativamente sobre 0 ambiente geram a diminuição da qualidade ambiental urbana.

A geração de resíduos sólidos e líquidos ocorre desde a fase de instalação do empreendimento até a fase de operação, quando as pessoas vão utilizar as edificações e realizar suas atividades. O RAP comenta que a destinação adequada dos resíduos é imprescindível para que não gere poluição, mas não indica soluções, como a separação e tratamento dos resíduos no local. Podendo ocorrer uma sobrecarga dos serviços públicos pela coleta de resíduos, bem como, impactos nas redes coletoras e nos depósitos de lixo do município.

O RAP afirma que cada edifício terá uma função diferente: o edifício mais baixo é destinado à locação de salas comerciais, o edifício intermediário é residencial e o edifício com mais pavimentos deve alojar escritórios. O boulevard, ou galeria, que percorre o térreo do empreendimento conta com lojas, restaurante, café, conveniências e serviços, ou seja, vai haver uma mistura de usos, podendo acontecer usos incompatíveis ou inconvenientes.

Sobre o aumento na circulação de veículos nas ruas circunvizinhas, o RAP não apresenta o impacto negativo sobre o meio biofísico, apenas aborda a questão do trânsito e de estacionamento. Mas, por se tratar de um grande empreendimento, com diversas atividades, deve ocorrer o aumento na geração de tráfego de veículos, que, consequentemente, vai diminuir a qualidade do ar.

Esse empreendimento é potencialmente poluidor, pois pode alterar negativamente o solo, a água e o ar, além, da mistura de usos do solo num mesmo terreno.

\section{Estilos de vida saudáveis}

Com o aumento do tráfego na região por causa das atividades do empreendimento, o RAP afirma que haverá impacto negativo significativo sobre o sistema viário. Assim, o projeto prevê a construção de três pavimentos de subsolo para estacionamento, com 552 vagas apenas para os proprietários de imóveis do 


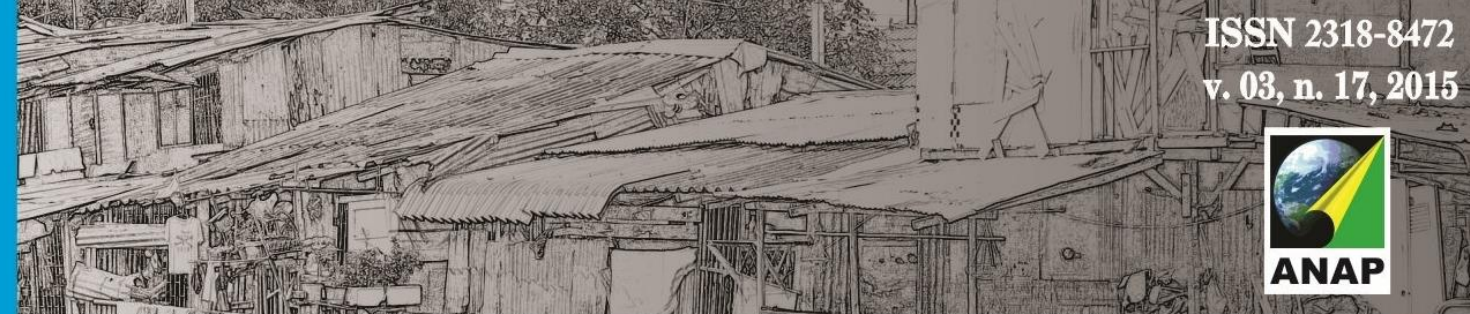

\section{Revista Nacional de}

Gerenciamento de Cidades

empreendimento, e a construção de espaços de embarque e desembarque de veículos, em forma de rótulas tangentes ao meio fio, na frente do complexo de edifícios para que as pessoas possam subir e descer dos veículos sem atrapalhar o trânsito das ruas.

É preciso pensar em ações que minimizam o impacto negativo do aumento na geração de tráfego de veículos na região, mas a construção de vagas de estacionamento, além de não ser suficiente para abranger todas as pessoas que devem circular pelo empreendimento, não resolvem o impacto do tráfego de veículos e suas consequências.

O impacto negativo ocasionado pelo aumento no fluxo de carros e suas consequências vão diminuir a qualidade ambiental urbana do bairro. A única maneira de tentar resolver o problema do trânsito é com restrições ao uso dos carros (Enrique Peñalosa ${ }^{8}$, 2013), sem citar os demais benefícios que estas restrições podem proporcionar, como a melhoria na qualidade do ar, a promoção de estilos de vida saudáveis, a diminuição da pegada ecológica, que resultarão em melhor qualidade ambiental urbana.

O projeto do empreendimento afirma que haverá um bicicletário com 20 vagas e, ainda, vestiários com armários e chuveiros para os que optarem pelo uso das bicicletas. As vagas para bicicletas sãouma pequena quantidade quando se pretende direcionar ou facilitar outras opções de mobilidade urbana.

Enfim, empreendimento apresenta-se direcionado ao uso de automóveis, sem apresentar outras opções de mobilidade, como a caminhada ou o transporte coletivo.

\section{Pegada ecológica}

Outro impacto relevante citado no RAP é a utilização de recursos naturais com a produção de bens edificados e o consumo de energia elétrica e de água

\footnotetext{
${ }^{8}$ Economista, especialista em administração pública, consultor nas áreas de trânsito e de urbanismo, ex-prefeito de Bogotá de 1998 a 2001.
} 


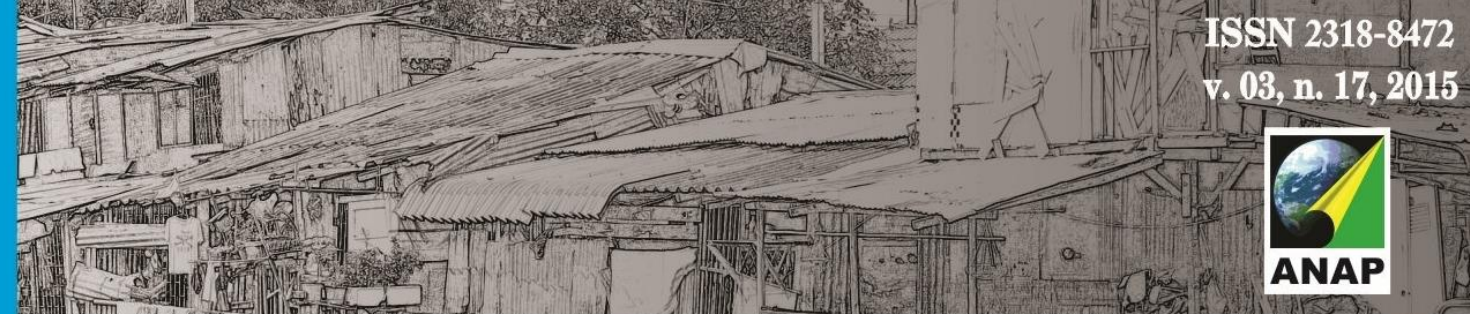

\section{Revista Nacional de}

Gerenciamento de Cidades

(fases de instalação e operação do empreendimento), consumo esse que deve aumentar com a realização das atividades no empreendimento, conclui o RAP.

As atividades desenvolvidas no local e o tamanho do empreendimento devem promover um significativo aumento no consumo de recursos naturais, aumento na geração de resíduos (como citado no critério usos potencialmente poluidores), aumento no uso de tecnologia suja, degradação ambiental e a não valorização da comunidade local.

\section{Conclusão do Relatório Ambiental Prévio sobre o empreendimento}

A conclusão do RAP do Complexo Tanguá Patrimonial Ltda. é de que os impactos ambientais devem ocorrer: sobre o meio físico seriam impactados negativamente o solo, o ar e a água e; o RAP afirma que o meio biótico poderia sofrer impactos negativos indiretos pelo uso dos recursos naturais e pela poluição; sobre o meio socioeconômico, o RAP informa que, haverá impacto negativo devido ao aumento dos serviços de abastecimento de água, de fornecimento de energia, de coleta, tratamento e disposição de esgoto e de resíduos sólidos, além do nível de ruídos.

O RAP também faz referência a possível interferência negativa sobre a drenagem urbana pelos lançamentos não monitorados de esgoto, impermeabilização inadequada do solo e supressão da vegetação.

Nas conclusões o RAP apresenta os variados impactos negativos que o empreendimento deveria provocar, alguns deles foram discutidos nos critérios analisados, como no critério pegada ecológica e usos potencialmente poluidores, outros, como os espaços livres e a cobertura vegetal não foram apresentados como impactos negativos, e, o critério verticalidade das edificações não foi avaliado no RAP, nem mesmo a questão do impacto sobre a drenagem da bacia hidrográfica em que se localiza o empreendimento. O RAP completa que a viabilidade do empreendimento será alcançada com a implantação de um Programa de Gestão Ambiental. 


\section{CONCLUSÃO}

De acordo com análise do RAP observou-se que não foram levados em consideração todos os impactos negativos que os três edifícios devem provocar sobre o meio biofísico da cidade. Apesar de alguns terem sido citados no RAP, não se desenvolveu a discussão do problema e os dados não foram apresentados.

Assim sendo, é possível concluir que o RAP do Complexo Empresarial e Residencial Tanguá Patrimonial não contemplou os impactos negativos do empreendimento e sua atividade quanto à qualidade ambiental urbana, com base nos princípios do Planejamento da Paisagem.

Da forma como têm sido feitos, com vistas ao crescimento econômico, os RAPs estão sendo elaborados e o ambiente está sendo degradado. Os limites e aptidões das paisagens pouco têm sido considerados para que o uso e a ocupação se realizem com empreendimentos e atividades adequados. As ações públicas são tomadas baseadas em prioridades políticas e econômicas e não nas aptidões e nos limites do ambiente.

O poder público, ao planejar adequadamente o ambiente, pode solicitar informações definitivas e pormenorizadas de aspectos relevantes para a área e para o empreendimento, além de planos de controle ambiental do empreendimento e sua atividade para os anos futuros. Se houvesse um adequado planejamento urbano os RAPs poderiam ser utilizados como instrumento para avaliar a qualidade do ambiente urbano.

Os estudos de qualidade ambiental urbana têm como objetivo auxiliar e propor medidas para a gestão e o planejamento do ambiente urbano. Nesse sentido, se os critérios de qualidade ambiental urbana, com base nos princípios do Planejamento da Paisagem, fossem trabalhados nos RAPs permitiriam a adequação dos usos e ocupações da terra às potencialidades das paisagens. Assim, os impactos negativos seriam reduzidos e a população urbana teria melhor qualidade ambiental. 


\section{REFERÊNCIAS}

BARTON, H.; TSOUROU, C. Health urban planning. A WHO guide to planning for people. Londres: Spon Press, 2000.

BRASIL. Lei Federal o 10.257 de 2001 - Estatuto da Cidade. In: MEDAUAR, O. (org.). Coletânea de legislação ambiental, Constituição Federal. São Paulo: Editora Revista dos Tribunais, 2008, p. 421-431.

CAVALHEIRO, F.; DEL PICCHIA, P.C.D. Áreas verdes: conceitos, objetivos e diretrizes para o planejamento. In: $1^{\circ}$ congresso brasileiro sobre arborização urbana $/ 4^{\circ}$ encontro nacional sobre arborização urbana, 4, 1992, Vitória. Anais I e II. 1992. p. 29-35. Disponível em http://www.geografia.ufpr.br/laboratorios/labs/arquivos/CAVALHEIRO\%20et\%20al\%20(1992).pdf. Acesso em 23/12/2011.

CURITIBA. Decreto o 838 de 1997 - Institui o Relatório Ambiental Prévio no Município de Curitiba. In: Leis Municipais: Paraná, Curitiba. Disponível em http://www.leismunicipais.com.br/legislacao-decuritiba/605139/decreto-consolidado- 838-1997-curitiba-pr.html. Acesso em 23/03/2013.

CURITIBA. Plano Municipal de Controle Ambiental e Desenvolvimento Sustentável. Curitiba, 2007. Disponível em http://www.curitiba.pr.gov.br/multimidia/00085327.pdf. Acesso em 11/06/2013.

DUARTE (Org.). RAP - Tanguá Patrimonial Ltda. - Complexo de Edifícios. Curitiba, 2009.

ESTÊVEZ, L. F. Relatórios Ambientais Prévios (RAPs) realizados em Curitiba (PR): uma análise com base nos princípios do Planejamento da Paisagem. Tese de doutorado. Universidade Federal do Paraná. Programa de Pós-Graduação em Geografia. 2014.

HOLMGREN, D. The essence of permaculture. 2001. Disponível em: www.nelsonavelar.com/permacultura/img/The/Essence-of-Permaculture.pdf. Acesso em 01/12/2011.

INSTITUTO DE PESQUISA E PLANEJAMENTO URBANO DE CURITIBA - IPPUC. Bairro Centro Cívico: Meio Ambiente. Curitiba, 2010. Disponível em http://ippucweb.ippuc.org.br/Bancodedados/Curitibaemdados/Curitiba_em_dados_Pesquisa.htm. Acesso em 17/09/2013.

LOMBARDO, M.A. Ilha de calor nas metrópoles. O exemplo de São Paulo. São Paulo, Hucitec, 1985.

$\mathrm{NUCCl}$, J. C. Qualidade ambiental e adensamento: um estudo de Planejamento da Paisagem do distrito de Santa Cecília (MSP). Tese de doutorado. Universidade de São Paulo. Programa de PósGraduação em Geografia Física. 1996.

$\mathrm{NUCCl}$, J. C. Qualidade ambiental \& adensamento urbano. $2^{a}$ edição. Curitiba: Edição do Autor, 2008, $142 \quad$ p. $\quad$ Disponível $\quad$ em http://www.geografia.ufpr.br/laboratorios/labs/arquivos/qldade_amb_aden_urbano.pd f. Acesso em 03/05/2010.

PEÑALOSA, E. Ex-prefeito de Bogotá diz que único jeito para trânsito é restringir carros. In: Folha de São Paulo (on line). Disponível em http://www1.folha.uol.com.br/cotidiano/2013/10/1350488-ex-prefeito-de-bogota-diz-que-unico-jeitopara-transito-e-restringir-carros.shtml. Acesso em 05/10/2013. 